\title{
A spatiotemporal analysis of urban resilience to the COVID-19 pandemic in the Yangtze River Delta
}

\author{
Xiansheng Chen ${ }^{1}$ (D) $\cdot$ Ruisong Quan ${ }^{1}$ (D)
}

Received: 16 July 2020 / Accepted: 22 December 2020 / Published online: 2 January 2021

(c) The Author(s), under exclusive licence to Springer Nature B.V. part of Springer Nature 2021

\begin{abstract}
The COVID-19 pandemic has severely affected the normal socioeconomic operation of countries worldwide, causing major economic losses and deaths and posing great challenges to the sustainable development of cities that play a leading role in national socioeconomic development. The strength of urban resilience determines the speed of urban social and economic recovery. This paper constructed a comprehensive evaluation index system for urban resilience under the COVID-19 pandemic scenario considering four dimensions-economy, ecology, infrastructure, and social systems-conducted a quantitative evaluation of urban resilience in the Yangtze River Delta of China, revealed its spatiotemporal differences and change trends, and proposed targeted strategies for improving urban resilience. The results show that (1) the Yangtze River Delta urban resilience system is growing stronger every year, but there are significant differences in the level of urban resilience, its spatial distribution and regional urban resilience. (2) In the Yangtze River Delta urban agglomeration, there is less distribution of areas with a higher resilience index, while those with high and medium resilience levels are more distributed. However, the resilience of most cities is low. (3) The resilience index of eastern coastal cities is significantly higher, and the resilience of cities under the COVID-19 scenario presents obvious east-west differentiation. (4) When constructing urban resilience, the individual situation of cities should be taken into account, measures adjusted according to local conditions, reasonable lessons drawn from effective international urban resilience construction, and reasonable planning policies formulated; it is important to give play to the relationship between the whole and the parts of resilience to achieve unified and coordinated development.
\end{abstract}

Keywords COVID-19 - Urban resilience $\cdot$ Temporal and spatial differentiation · Yangtze River Delta $\cdot$ China

Ruisong Quan

quanrs@yeah.net

School of Political Science and Public Administration, East China University of Political Science and Law, No. 555 Longyuan Road, Shanghai 201600, China 


\section{Introduction}

On February 28, 2020, the WHO raised the risk of global transmission and the impact of a COVID-19 pandemic to "very high" from "high" (Wang et al. 2020a). Since then, the global pandemic has developed rapidly. On March 7, 2020, the number of confirmed cases worldwide exceeded 100,000, and the number of affected countries exceeded 100 the next day. According to the WHO's daily COVID-19 report, as of 10:00 central European time on June 27, 2020 (16:00 Beijing time), in just the previous day, the number of confirmed COVID-19 cases outside China had increased by 179,292 to 9,567,876, and the number of deaths outside China had increased by 6866 to 486,480. Globally, that same day, the number of confirmed COVID-19 cases increased by 179,316 to $9,653,048$, and the number of deaths increased by 6866 to 491,128 (Huang et al. 2020). Cities with high population concentrations, such as Wuhan, New York, Milan, and Madrid, were hit the hardest. Cities have become the engines leading countries' social and economic development, and the length of time required for urban social and economic recovery depends on the resilience of the urban area. The analysis, evaluation, and improvement in urban resilience have become important issues urgently requiring a solution among government administrators and academia (Percy et al. 2019).

"Resiliency" comes from the Latin word "resilio," meaning to "bounce back" or to return to your former status. In 1973, Holing, a Canadian ecologist, first introduced the concept of resilience into the field of ecology and defined urban resilience as "the ability of an ecosystem to adapt to the process, sustain resistance and restore balance after a short impact" (Holling 1973). "Resilience" is a controversial concept, and different disciplines have different research emphases and understandings of resilience. Compared with adaptability, urban resilience is more representative: Resilience originally referred to the possibility that something squeezed will return to its original state after being squeezed; vulnerability focuses on the multiple effects of a single risk disturbance on an object. Urban resilience includes the ability of cities to withstand disasters and, more importantly, to bounce back under risk and to anticipate, prevent, respond to and recover from extreme disasters (Diaz-Sarachaga and Jato-Espino 2019). The strength of urban resilience lies in the area's ability to respond to emergencies and adapt to long-term risks. The higher the resilience level is, the lower the vulnerability, and the stronger the impact resistance and absorption capacity (Vejmelková et al. 2012). Resilience can be divided into three types: regional, urban, and community disaster resilience (Zhou et al. 2012). Urban areas are a complex social and ecological system in which there are various elements that are interrelated and influence each other. The Rockefeller Foundation of the United States pointed out that "urban resilience" is the ability of individuals, communities, institutions, enterprises and systems in an urban area to survive, adapt and grow under the impact of various chronic and acute pressures. It has seven characteristics: reflexivity, inclusiveness, comprehensiveness, robustness, redundancy, flexibility, and resourcefulness (Paidakaki and Moulaert 2018). Urban resilience exists when the different subjects in the complex socioecological system of urban areas can successfully confront the various chronic and acute pressures that exist locally, such as natural disasters, economic crises, and social and political turbulence, through reasonable preparation and optimal coordination among system components (Fastiggi et al. 2020). Thus, resilience includes the prevention, response, recovery, and long-term adaptation necessary to protect the public security, social order, and economic construction of urban areas from being affected. 
Domestic scholars introduced the theory of resilience to China in the 1980s; combined with the requirements of urban sustainable development targets and according to the characteristics of China's regional development, a large number of empirical studies were then conducted that addressed urban resilience. Li et al. studied the development of China's infrastructure resilience, ecological resilience, and urban resilience in a cross section at a single point in time from the perspectives of the whole country, urban clusters, and provinces (Li et al. 2019). Huck et al. (2020) examined network construction from the perspective of networks and quantitatively evaluated the urban network resilience of urban agglomerations in the middle reaches of the Yangtze River with the help of complex network theory and the Gephi evaluation structure model (Bostick et al. 2018). Zhao et al. (2019) recently evaluated the urban resilience of Dalian, China, based on the scale-density-form and introduced spatial analysis, quantitative assessment of urban resilience, model construction, and other methods of assessing the ecological footprint and ecological resilience according to urban density, providing relatively sufficient technical means for the study of urban resilience. Zhao quantitatively evaluated Wuhan's ability to cope with flooding from rain based on resilience theory and an evaluation model of the approximate ideal solution sequencing method. Li performed a comprehensive evaluation of China's urban resilience by constructing a comprehensive resilience index system combined with the spatial analysis method and proposed corresponding countermeasures for the development of urban resilience.

In the 1990s, the concept of resilience was widely studied within different disciplines. Scholars' research on resilience extends from ecology to engineering, society, the economy and management, including social ecosystems, social science, psychology, and management (Bonanno et al. 2007; Chang et al. 2014; Bellamy et al. 2017; Dennis et al. 2019). The concept of resilience has been widely applied in disaster science and has become a new concept within disaster response and management. With the increase in urban uncertainty and disturbance factors, urban resilience has gradually become a hot issue in society and academia. In terms of the types of disaster events in resilience assessment, they involve various types of emergencies, such as natural disasters, accidents, public health crises, and social security, among which the majority of resilience assessments address natural disasters. These disasters include earthquakes (Inoue and Todo 2019), typhoons (Macaskill 2019), heavy rain, and floods (Cho and Chang 2017; Chen et al. 2020). From the perspective of a spatial scale analysis of resilience assessment, the span covers multiple scales, such as country, city, and community. From the perspective of quantitative resilience evaluation methods, assessment mainly includes two categories: evaluation based on the system function curve and evaluation based on the index system. First, the system function curve of the resilience calculation method laid a foundation for the quantitative evaluation of resilience, whether for a single unit of land or multiple areas; based on the definition of the system, the system function curve can adopt different variables. However, such evaluation methods require a large amount of data and the calculations are difficult in practical application. Scholars represented by Burton evaluated resilience from the perspective of engineering and defined "community seismic resilience" as the ability of communities to mitigate and absorb losses caused by disasters, to take measures to recover from disasters, and to cultivate the ability to cope with disasters in the future. Community earthquake disasters mainly destroy community infrastructure, and the functional change in the infrastructure system can be described by the system function curve. Second, the resilience evaluation method based on the index system can comprehensively evaluate the resilience level of the system, but the construction of the index system and factor weight assignment are subjective. Cutter et al. (2008) observed that the resilience model of the system function curve 
does not consider social and economic factors (Cutter et al. 2014). Therefore, by taking into account the external environmental factors of the community and both rapid events (such as hurricanes and earthquakes) and chronic events (such as global climate change and sea level rise), Cutter et al. (2008) proposed a community resilience assessment indicator system constructed from the six aspects of ecology, economy, society, infrastructure, system, and community capacity. Cutter, based on the DROP model, eliminated the ecological dimension and constructed a community baseline resilience index that includes five aspects: society, economy, system, infrastructure, and community capital. Based on the cases of more than 20 cities worldwide, the Rockefeller Foundation proposed an urban resilience framework and a comprehensive urban resilience index (Croese et al. 2020) that consists of four key areas: economy and society, health and welfare, infrastructure and ecosystem, leadership and strategy. Each area has three resilience goals and 52 qualitative and quantitative indicators. Klimek et al. (2019) used the ARUP index system to propose a resilience index that categorizes the resilience of American cities. To examine the case of sudden disasters, Kayunga builds matrices according to four capital types and four disaster prevention stages to build a community disaster resilience index system. The four capital types include social capital, economic capital, physical capital, and human capital, and the four disaster prevention stages include mitigation, preparedness, response, and recovery.

After the 1990s, Folke et al. (2004) further proposed the theory of the "adaptive cycle," which is used to represent the interaction and evolution of resilience in the "socioecological" system after external impact. Based on discussions of the community resilience assessment index, Cariolet et al. (2018) carried out urban resilience assessments for American communities in the context of complex disasters and created the urban resilience assessment dimension. Ujeyl and Rose (2015) also carried out an in-depth study on the definition and measurement of economic resilience. Bruneau et al. (2003) built a quantitative model to calculate the resilience of infrastructure engineering considering the aspects of robustness and rapidity. Sherrieb et al. (2010) analyzed the Mississippi County Community Resilience Index based on archival and demographic data. Bozza et al. (2015) attempted to construct indicators based on the direction and content of community assessment to form a resilience index framework for the assessment of US coastal areas. Clarke (2017) established a disaster resilience assessment (DROP) model based on the community level, thus providing a quantitative evaluation standard for social resilience. Based on research on community earthquake disaster resilience, Zhong et al. (2020) defined the resilience of the community as the "community's capacity to absorb damage and restore quickly" and proposed resilience properties, including consistency, redundancy, counseling, and rapid resilience. The resilience system is divided into four interrelated subsystems: economic resilience, ecological resilience, engineering resilience, and social resilience. Hossain et al. (2019) summarized the existing definition of resilience and believed that "Resist and recover" are the three main characteristics of resilience systems. Due to the great differences in the perspectives of definitions, the methods for achieving 'resilience" in different research fields, and the different connotations of the same concept applied by different researchers, a large number of scholars have discussed the concept of "resilience" in depth. Although there is no consensus on the concept, Rees's three characteristics of resilience are widely recognized and lay the foundation for the evaluation of resilience systems (Rees et al. 2016). Wang et al. (2018) analyzed and compared the similarities and differences between urban resilience and sustainable development, pointed out that urban resilience could be used as a new means to achieve sustainable development, and proposed a set of widely recognized planning and design approaches to improve urban resilience, including three strategies: multifunction, redundancy, and template (Wang et al. 2018). 
In summary, academic research varies based on the background, concept, content, and so on, and at present, research on urban resilience is still in its infancy. Based on this review of the related literature at home and abroad, including research on urban resilience theory and urban regional economic resilience, studies of the theory of urban regional ecological resilience are relatively lacking. Relatively speaking, the research perspectives involved are geography, the urban system perspective, and urban topics such as policy, urban planning, and management perspectives, making this a relatively wide field. In addition, many scholars have focused on the region as the main component, but the individual cities play an important role, as does the status of the main urban body.

Currently, under the context of the pandemic, the study of urban resilience is becoming a major scientific problem that affects and restricts the sustainable development of modern cities, and a set of scientific theoretical systems is urgently needed to allow analysis of the characteristics and construction problems in urban resilience based on different spatial scales and regions (Wilson et al. 2016). A framework of urban resilience assessment should be constructed based on pandemic disasters to comprehensively assess the state of urban resilience construction and development and promote healthy and stable urban development (Trencher et al. 2016).

In view of the above overview of resilience studies and the recognized lack of research, and in view of the current worldwide COVID-19, the main purposes of this study are (1) to explore the components of urban resilience based on the COVID-19 scenario and to establish an urban resilience assessment system in the Yangtze River Delta; (2) to conduct an in-depth analysis of the Yangtze River Delta urban agglomeration over the last 15 years, from 2003 to 2017, based on the urban resilience index and spatiotemporal differentiation characteristics under the pandemic scenario, and from the results of the spatiotemporal differentiation analysis, analyze the development of urban resilience in China's Yangtze River Delta; and (3) to reveal the main factors affecting urban resilience and provide important cognitive basis and theoretical guidance for urban pandemic response, urban resilience system construction, urban recovery, and future urban healthy development.

\section{Overview of research area}

The Yangtze River Delta is located along the Yangtze River and the East China Sea coast (as shown in Fig. 1). Based on the "Yangtze River Delta urban agglomeration development plan" approved by the State Council in May 2016 and the Central Committee of the Communist Party of China in December 2019, the State Council issued the "Yangtze River Delta regional integration development plan," outlining the scope of central planning for urban development. Based on the increasing newly urban area of the Yangtze River Delta economic association in 2019, a total of 33 cities were characterized, and the urban and new urban areas were included in the Yangtze River Delta economic association as the core urban area for Yangtze River Delta economic development. Compared with other areas, the urban population in this area was highly concentrated, with high mobility and high employee turnover. There are frequent urban political, economic and cultural activities, and a healthy social division of labor (Kuo et al. 2019). The Yangtze River Delta is a combination of the "gold coast" and a "golden waterway": a flat terrain, fertile land, convenient transportation, and a vast hinterland providing superior natural conditions and a superior geographical location. Since the Ming and Qing Dynasties, it has been China's most economically developed region. In the early days of the People's Republic of China, although the populations of Jiangsu, Zhejiang, and Shanghai accounted for only 1/10 of the national population, their economic value and industrial output accounted for $1 / 6$ and nearly $1 / 4$ of 


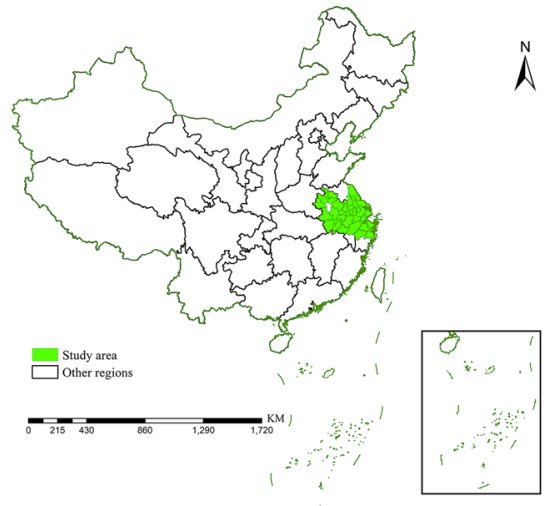

(a)

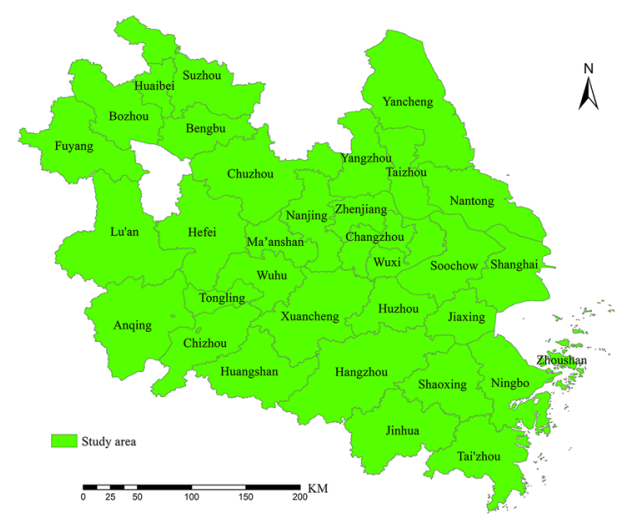

(b)

Fig. 1 The study area: a the location of the Yangtze River Delta Urban Agglomerations in China; b the administrative division of the Yangtze River Delta Urban Agglomeration (1, 2, 3, and 4 represent Taizhou, Ma'anshan, Changzhou, and Wuxi, respectively)

that nationally, respectively. Influenced by the planned economy system and the shift in the national industrial development center, the economy and industry of the two provinces and one urban area have developed to some extent, but the pace of development is slow. From 1952 to 1990 , the economic aggregate of these two provinces and one urban area increased from 16.14 to $16.56 \%$, and its industrial output value accounted for less than a quarter of the country's total. Since the reform and opening up, especially since the 1990s, the economic development of the Yangtze River Delta has entered a new stage of modernization. The 14th National Congress of the Communist Party of China set the reform goal of establishing a socialist market economy system and proposed a major strategic plan that included "the development and opening up of Shanghai Pudong as a pioneer to drive the economic development of the Yangtze River Delta region." The gradual deepening of the reform and opening up and the continuous improvement in the external environment fully unleashed the development potential of the Yangtze River Delta. With the rapid development of modern industry and the regional economy, the Yangtze River Delta now occupies a leading position in China's economic region. In the domestic and foreign markets, competition has gradually formed some new competitive advantages. However, there are always both positive and negative aspects. With the development of comprehensive economic and regional strength, the economic losses and impacts to the strength of this region caused by COVID-19 have been immeasurable, so it is particularly important to study the resilience of cities in this region.

\section{Materials and methods}

\subsection{Data sources}

The specific index data from 2003 to 2018 of this article are taken from the statistical yearbooks for Shanghai (http://tjj.sh.gov.cn), Jiangsu (http://tj.jiangsu.gov.cn), Zhejiang (http://tjj.zj.gov.cn), Anhui (http://tjj.ah.gov.cn), and various municipalities. The data for the ecological environment resilience index from 2003 to 2018 are taken from the 
Shanghai environment gazette (https://sthj.sh.gov.cn/), environmental conditions in the Jiangsu Province gazette (http://hbt.jiangsu.gov.cn), the environmental conditions in the Zhejiang province bulletin (http://sthjt.zj.gov.cn/L, and the Anhui Province environmental gazette (http://fbh.anhuinews.com/). Some data for the economic resilience index are taken from the statistics bulletin of the national economy and social development for Shanghai (http://www.shanghai.gov.cn/), Jiangsu Province (http://www.jiangsu.gov.cn/), Zhejiang Province (http://tjj.zj.gov.cn/), and Anhui province, Due to the absence of individual data, the values of adjacent years are inferred.

\subsection{Research methods}

\subsubsection{Urban resilience measurement model (TOPSIS model)}

The TOPSIS method was first proposed by C. L. H. Wang and K. Yoon in 1981 (Wang and Elhag 2006). It is a sorting method based on the proximity of a limited number of evaluation objects to the idealized goal; it evaluates the relative merits of existing objects (Dutta et al. 2019). The TOPSIS method is a sorting method that approximates the ideal solution, and it only requires that each utility function is monotonically increasing (or decreasing). It is a common and effective method in multiobjective decision analysis, also known as the pros and cons solution distance method (Chen and Li 2013). The TOPSIS evaluation method was chosen in this study for the following reasons. The TOPSIS method is a commonly used comprehensive intragroup evaluation method that can make full use of the information of the original data, and its results can accurately reflect the differences among evaluation schemes (Beskese et al. 2015). The basic process is based on the normalized original data matrix, and the cosine method is used to determine the optimal and worst schemes in the finite scheme. Then, the distance between each evaluation object and the optimal and worst schemes are calculated to obtain the relative proximity between each evaluation object and the optimal scheme; this is taken as the basis for the evaluation. The method has no strict limitation on the data distribution or sample content, and the data calculation is simple and easy (Boland et al. 2020). To unify the evaluation criteria (with each index value being between 0 and 1), raw data with different dimensions must be standardized (Jones and Parker 2019). The main function of data standardization is to eliminate the dimensional relationship between variables so that data can be comparable (Moghadas et al. 2019). In this study, the extremum standardization method was used to standardize the original data in the index system. Using the entropy weight method for statistical weight, evaluation indices and the TOPSIS method are applied to resilience for selected cities in the Yangtze River Delta city to conduct a quantitative analysis and comparison. Because the entropy weight method of weighting the index performs calculations according to the measure index variation data, thus greatly reducing the subjective factors that drive interference, the value is limited by the TOPSIS method as a point in $n$-dimensional space, and the relative distance between each point and ideal is calculated for sorting. This method not only reflects the relative relationship between different objects but also has the advantage of making full use of the original data with less information loss (Boland et al. 2020).

Step 1: The first step is to convert all indicators into extremely large indicators; the indicator standardization formula is as follows: 


$$
\begin{aligned}
& \text { Positive indicators: } z_{i j}=\left[\frac{x_{i j}-\min \left(x_{j}\right)}{\max \left(x_{j}\right)-\min \left(x_{j}\right)}\right] * 0.9+0.1 \\
& \text { Reverse indicators: } z_{i j}=\left[\frac{\max \left(x_{j}\right)-x_{i j}}{\max \left(x_{j}\right)-\min \left(x_{j}\right)}\right] * 0.9+0.1
\end{aligned}
$$

where $z_{i j}$ is the normalized matrix, which represents the standardized evaluation index value for urban resilience from the perspective of coupling disasters; $x$ is an index; $i$ is the number of rows, namely the evaluation of the target urban area; $j$ is the number of columns or the index name. The calculation is multiplied by 0.9 and 0.1 is added to calculate the weight more accurately in the entropy weight method, which does not affect the result.

Step 2: The second step is to use the standardized index system: $z_{i j}, k=\ln \frac{1}{n}$. To adjust the coefficient, $n$ is the number of cities that need to be evaluated in the urban resilience assessment. We calculate the annual information entropy $E_{j}$ as follows:

$$
E_{j}=k \sum_{i=1}^{n}\left[\left(z_{i j} / \sum_{i=1}^{n} z_{i j}\right) \ln \left(z_{i j} / \sum_{i=1}^{n} z_{i j}\right)\right]
$$

Step 3: The third step is to calculate the weight of each evaluation index $z_{i j}$ in $W_{j}$, where $m$ is the number of indicators we selected to assess the resilience of cities in the face of COVID-19:

$$
W_{j}=\left(1-E_{j}\right) / \sum_{j=1}^{m}\left(1-E_{j}\right)
$$

Step 4: In the fourth step, the entropy weight and TOPSIS methods are combined to build a comprehensive evaluation model of urban resilience. Finally, based on the calculation results of the model, the weighted standardization of the urban resilience index for the Yangtze River Delta each year is comprehensively evaluated, and its expression is as follows:

$$
Z=W_{j} z_{i j}
$$

Step 5: The fifth step is to construct the weighted standardized decision matrix $Z$ for each year. $Z$ is the matrix of the urban resilience index for cities in response to COVID-19 after being weighted, assuming that each year there are $n$ objects to be evaluated, and the weighted standardized decision matrix of $m$ evaluation indices is:

$$
Z=\left[\begin{array}{cccc}
Z_{11} & Z_{12} & \cdots & Z_{1 m} \\
Z_{21} & Z_{22} & \cdots & Z_{2 m} \\
\vdots & \vdots & \ddots & \vdots \\
Z_{n 1} & Z_{n 2} & \cdots & Z_{n m}
\end{array}\right]
$$

Define the maximum value in a specific index of urban resilience evaluation in a specific year:

$$
Z^{+}=\left(Z_{1}^{+}, Z_{2}^{+}, \ldots, Z_{m}^{+}\right)=\left(\max \left\{Z_{11}, Z_{21}, \ldots, Z_{n 1}\right\}, \max \left\{Z_{12}, Z_{22}, \ldots, Z_{n 2}\right\}, \ldots, \max \left\{Z_{1 m}, Z_{2 m}, \ldots, Z_{n m}\right\}\right)
$$


Define the minimum value in a specific index of urban resilience evaluation in a specific year:

$$
Z^{-}=\left(Z_{1}^{-}, Z_{2}^{-}, \ldots, Z_{m}^{-}\right)=\left(\min \left\{Z_{11}, Z_{21}, \ldots, Z_{n 1}\right\}, \min \left\{Z_{12}, Z_{22}, \ldots, Z_{n 2}\right\}, \ldots, \min \left\{Z_{1 m}, Z_{2 m}, \ldots, Z_{n m}\right\}\right)
$$

Define the distance between the $i(i=1,2, \ldots, n)$ evaluation object and the maximum value:

$$
D_{i}^{+}=\sqrt{\sum_{j=1}^{m}\left(Z_{j}^{+}-Z_{i j}\right)^{2}}
$$

Define the distance between the $i(i=1,2, \ldots, n)$ evaluation object and the minimum value:

$$
D_{i}^{-}=\sqrt{\sum_{j=1}^{m}\left(Z_{j}^{-}-Z_{i j}\right)^{2}}
$$

Step 6: The sixth step is to calculate the final resilience index of the $i(i=1,2, \ldots, n)$ evaluation object in each year. $S_{i}$ represents the resilience of the city in responding to COVID-19 in a given year as follows:

$$
S_{i}=\frac{D_{i}^{-}}{D_{i}^{+}+D_{i}^{-}}
$$

Step 7: The last step, the average resilience value $R$ for each year's city resilience index to COVID-19, was calculated as follows:

$$
R=\frac{1}{x}\left[\sum_{y=1}^{x} S_{i}(y)\right]
$$

The model constructs a comprehensive evaluation system of urban resilience considering the four aspects of urban economic resilience, ecological resilience, infrastructure resilience, and social system resilience in the context of the pandemic. According to historical data, the urban resilience for each year and the average urban resilience for each year are obtained for the overall evaluation. In the formula, $R$ represents the urban resilience index, $x$ is the number of years, and $y$ is the one year. $S_{i}$ is the degree of fit between the $i(i=1,2, \ldots, n)$ evaluation index and the positive idealized target, namely the resilience index, and $S_{i}(y)$ is the resilience index of an urban area in a certain year.

\subsubsection{Selection of urban resilience indicators}

Urban resilience means that urban areas can withstand disasters through their own abilities, reduce disaster losses, and reasonably allocate resources to recover quickly from disasters. In the long run, cities can learn from past disasters and improve their adaptability to disasters (Wang et al. 2020b). Resilience, as a core concept, has been applied to various types of human settlements (such as urban or rural environments) and different fields (such as climate change or sustainable development) (Orencio and Fujii 2013). Some scholars have conducted research on improvements in resilience in response to a specific disaster (such 
as earthquakes, fires, and hurricanes) in a specific city or region. Although there is no unified definition, it has become a consensus to discuss the connotation of urban resilience from the economic, social, technological, and organizational dimensions (Stanke et al. 2012). From the existing research, scholars use experience for reference and apply theoretical deduction to construct an index system, evaluation model, and empirical analysis. Building a preliminary theoretical analysis framework and research system provides a good foundation for further study; these have mainly focused on the connotation of resilience and an index system for architecture; study has been proposed on the construction of an index system and evaluation model, but there is less empirical research (Manyena 2006). According to the above interpretation of the urban resilience concept and after reviewing the resilience index of domestic and foreign cities and drawing lessons from the evaluation index system of urban resilience constructed by Burton, Cutter, and Cai, it is determined that a comprehensive consideration of the Yangtze River Delta's urban development level must be based on the relative and absolute difference between the comprehensive measures of urban resilience. Under the current situation of governance over the COVID-19 outbreak, indicators capturing the dimensions of pandemic-related urban resilience must be identified through a systematic, scientific process and adhere to the principles of representativeness and accessibility. The four subsystems identified are the economy (Chirisa et al. 2016), ecology, infrastructure (Herbeck and Flitner 2019), and social systems (Tkatch et al. 2017). Based on the analysis of the concept of resilience shown by cities in response to disasters and combined with expert opinions, the evaluation framework of urban resilience is adjusted and corrected accordingly. We chose a temporally dynamic perspective from 2003 to 2017 to reflect urban resilience in different periods. The degree of the urban resilience index varies from year to year, such as annual GDP, the number of hospitals and health centers, and basic medical insurance, and the dynamic display illustrates these changes over different years. Four time points with equal distances in this dynamic period are selected for representation. A total of 26 indicators were selected, and the composite index method was adopted to build a comprehensive evaluation index system of urban resilience. For some indices, it is difficult to directly identify accurate quantitative data, so indirect measurement evaluation and related factors were selected according to the relevant analysis, and the relationship between the elements was studied. A comprehensive analysis was performed to identify the highly relevant variables (e.g., Pearson $R>0.70$ ), and 26 indicators were ultimately selected (Table 1).

Economic resilience is the key to urban resilience in a COVID-19 scenario (Ompad et al. 2018), and each element in the dimension of economic resilience is closely related to health. Economic diversification, when a pandemic such as COVID-19 occurs, can prevent the urban economic system from suffering a devastating blow due to economic dependence on a single industry. In the recovery process, diversity can also provide a variety of economic resources and service support, and so the annual GDP of the assessed objects is selected for representation. The expenditures in the local fiscal budget and the total tax revenue of the region not only provide a financial guarantee to prevent harm from the pandemic and support urban recovery and construction but also help solve problems related to employment resilience, especially after the occurrence of emergencies. Cities with an insufficient economic base need to rely on other resources to maintain urban and rural resilience such as the year-end balance of savings. The pandemic has had the most severe impact on tertiary industry, and thus the greater the proportion of tertiary industry is, the greater the impact caused by the pandemic. This will further lead to a slower recovery speed. Therefore, the proportion of tertiary industry in GDP is selected to represent economic resilience. Scientific enterprise expenses capture the support given to address 


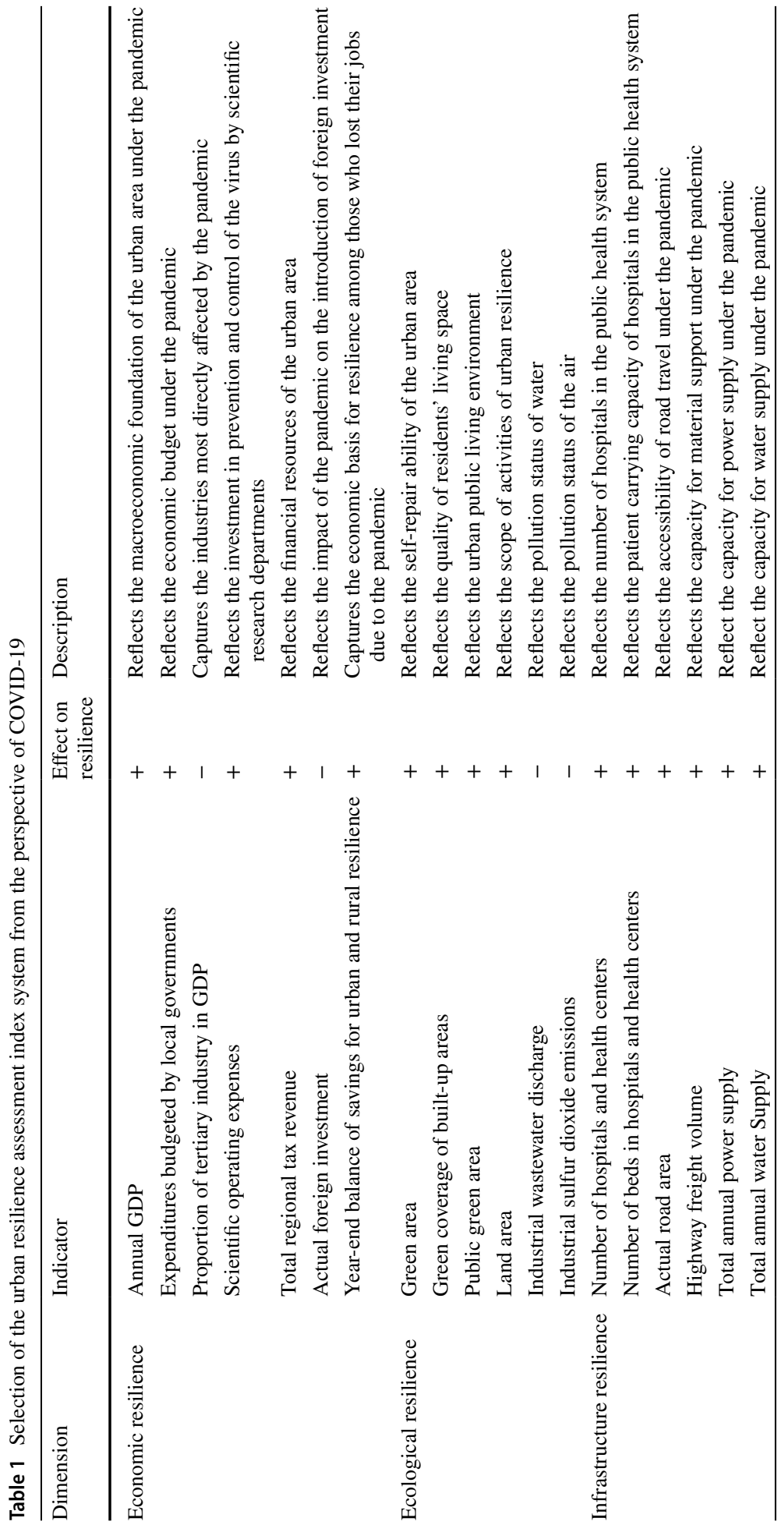




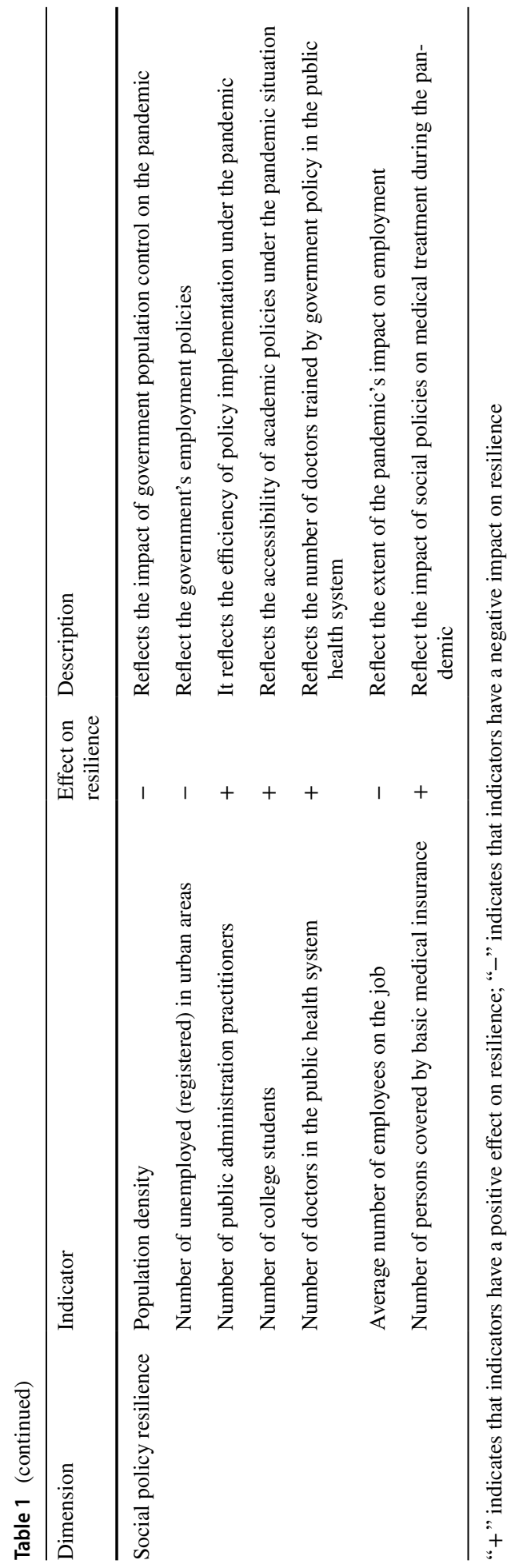


COVID-19. The greater the expense is, the more proportional it is to the damage caused by COVID-19. The impact of COVID-19 on foreign investment is self-evident, and the reduction in foreign investment caused by COVID-19 should not be exempted from consideration. When there has historically been more foreign investment, the reduction caused by COVID-19 will increase the difficulty of urban economic recovery.

Ecological resilience is fundamental to resilience and the fight against COVID-19 (Lafortezza and Sanesi 2019). Urban natural environments can provide many ecosystem services, generate public health synergies, and benefit human health and well-being. Among them, green space area and the green coverage rate in built-up areas affect the living environment and indirectly affect public health. The green ecological environment can effectively alleviate the harm brought by pandemic disasters. Plants can retain rainwater and effectively reduce the range of virus transmission in the air. Green vegetation is conducive to absorbing or removing substances such as $\mathrm{CO}_{2}$ and particulate matter, alleviating virus transmission, the urban heat island effect, and the public health damage caused by the heat island effect. A green ecological environment and public green space are also conducive to active exercise, stress relief, and mental health recovery among residents. Air quality consistently affects residents' health, especially respiratory and circulatory health, and air pollution can thus accumulate and exacerbate the effects of COVID-19. The land area was selected as a representative element to measure the danger of the COVID-19 pandemic in cities. The greater the urban land area is, the sparser the population, and the smaller the influence of factors driving the COVID-19 pandemic. The coverage rate of green vegetation in the urban area is conducive to alleviating pollution from the emission of industrial wastewater and sulfur dioxide in the urban area, which indirectly affects the quality of life and reduces the risk of being infected by COVID-19. It is conducive to the restoration and development of urban construction.

Infrastructure resilience is the foundation of urban resilience in response to COVID19 (Lankao 2010). The influence of the urban environment on public health has been a popular research topic since the beginning of the twenty-first century. The urban public health system is an important embodiment of the resilience of infrastructure; it includes health administration departments at all levels, disease prevention and control agencies, health supervision agencies, medical treatment institutions and public health research institutions (Lhomme et al. 2013). Considering the principle of data accessibility, we chose hospitals and health centers to represent the carrying capacity of the city when addressing the COVID-19 pandemic and the number of beds in the hospitals to represent their carrying capacity. Actual road area represents accessibility to vehicles; accessibility to highway freight volume and other common responses plays an important role in evacuation and the entry of critical materials after a disaster; the total annual power supply and materials supply are selected to indicate power support after health hazard events. By selecting the total annual water supply, the capacity of water supply facilities in urban infrastructure can be measured, which plays an important role in emergency rescue and is an essential part of residents' lives.

The resilience of social policies determines the response and direction of development after COVID-19 (Muñoz-Erickson et al. 2014). China's unique political system and government-led urban development model enable government organizations to play a leading and dominating role in urban development. Moreover, the policy system determines the urban response to the coronavirus pandemic. System integrity determines the degree to which the defense system is able to directly affect the response to the coronavirus. Population density is one of the main directions of national regional management, and urban resilience is closely related to social welfare and public services. The reform of the Yangtze 
River Delta cities household register system made some achievements, but the frequent population movements and the need to balance the interests of all parties mean that social problems resulting from household register discrimination are still widespread. This has become one of the most basic livelihood issues; population density indirectly reflects system integrity, and thus it is selected as the basic manifestation of system integrity. The more complete the registration of the urban unemployed is, for example, the better able the government will be to adopt corresponding countermeasures or policies. The urban population suffered massive unemployment due to COVID-19. The unemployment rate in an area well reflects the measures taken by the urban area to protect the unemployed and indirectly reflects the implementation effect of government policies. Public administration, social organizations, resilience workers and resources, benefits, and access to timely information will all be part of the coronavirus emergency policy, and they may tend to lag. Heads of state government departments, organizations, enterprises, and institutions provide experience, knowledge reserves, and social networks, making them one of the important mediums through which cities obtain relevant policy information. These indirectly reflect the urban policy system, so the number of representatives is chosen to reflect the known degree of policy. Organizational coordination determines the timeliness of resource integration and the effectiveness of system implementation and affects the restoration of social cohesion. The number of students in colleges and universities can well reflect the effectiveness of policy transmission by government organizations and departments. College and university students have a certain ability to distinguish the sensitivity and accuracy of information and can convey government policies and instructions well, which indirectly represents the coordination of the organizational system. Every second counts in a disaster, and the timeliness of the emergency response determines the consequences of the hazard and the damage. The number of physicians practicing is the key to the overall improvement in health standards and directly affects the quality of the health system. The resilience of the health system often depends on the retention of health personnel, which is characterized here by the number of physicians. The average number of incumbent post workers can reflect the impact of the pandemic on China; the more the people there are holding this position, the greater the impact will be, and the rate of recovery will vary depending on the area of impact (Fang et al. 2017). The number of basic health insurance enrollees is also an important indicator during a pandemic and provides a good indication of the financial impact of the pandemic on individuals. The more the enrollees there are, the greater their relative resilience will be.

\section{Results}

\subsection{General trends in urban resilience in the Yangtze River Delta}

This article constructs an urban resilience index system for the Yangtze River Delta urban agglomeration under a new coronavirus pandemic scenario using entropy-weighted TOPSIS synthesis. The urban resilience index of 33 cities was obtained by the evaluation method and calculated inductively for each urban area in the Yangtze River Delta for the past 15 years. Examining trends in the average resilience index, the overall resilience of urban agglomerations showed a sustained growth trend for the Yangtze River Delta region. 


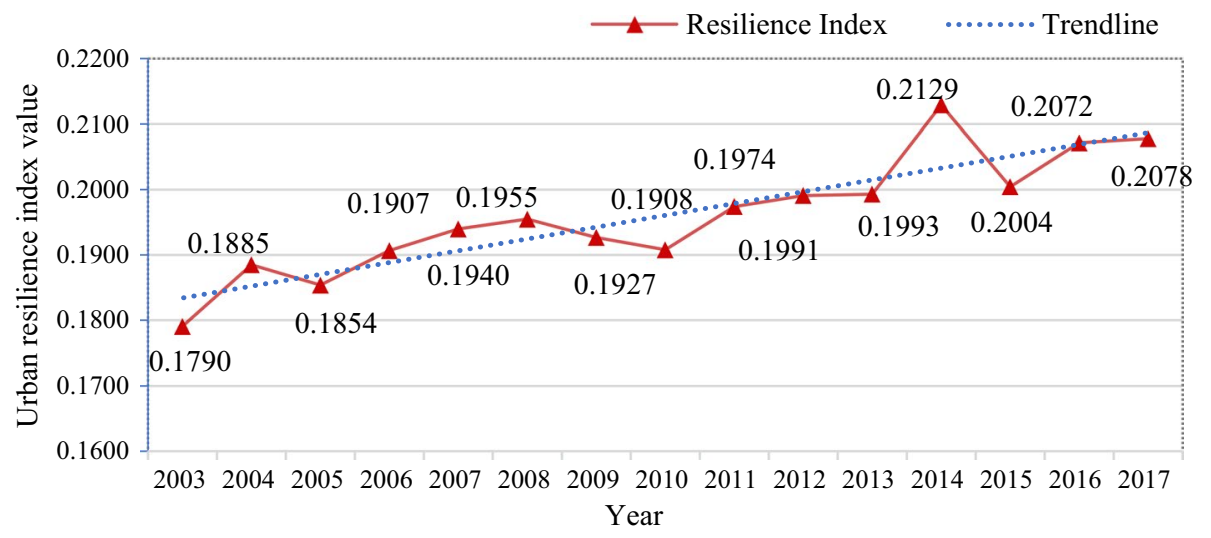

Fig. 2 Urban resilience development trend in the Yangtze River Delta

In 2014, the urban agglomerations were in a "prime" period of resilience growth, as shown in Fig. 2:

(1) 2003-2004: With China's formal accession to the WTO, China's economy began growing at a relatively rapid pace, which corresponds to the need for a more efficient and effective response to the global economic crisis. Pandemics have had a positive impact on resilience, with the sporadic outbreak of SARS in 2002 causing social panic and suffering among urban social systems. The resilience of Yangtze River Delta cities declined sharply in 2003. A report released by the National Bureau of Statistics on October 10, 2005, pointed out that due to the return of rational investment growth, total investment in the Yangtze River Delta Region as a percentage of GDP had been on a downward trend for many years. Statistics show that overheating was kept under control for regional investment, and as a result, the overall resilience index fell. In the first quarter of 2011, 16 cities invested 302.6 billion yuan in fixed assets, a year-on-year increase of $15.5 \%$, with three cities also experiencing negative growth. In most cities, the growth in socially owned fixed asset investment was significantly lower than that in gross regional product. The outbreak of avian influenza in 2004 affected the urban economy, so the overall trend in the urban resilience index was downward; then, the CDC and WTO managed the outbreak, and the Yangtze River Delta's urban resilience recovered the following year. (2) 2005-2008: During this period, urban resilience showed healthy development, and the urban resilience of the Yangtze River Delta showed a steady increasing trend. This peaked in 2008, and the Yangtze River Delta's resilience index decreased under the financial crisis of 2008. (3) The 2010-2013 financial crisis caused global market demand to weaken, and regional GDP shifted from growth to slow growth. The Yangtze River Delta saw a large number of unemployed people, an increase in the unemployment rate, and a corresponding increase in the number of employed public managers, resident savings, the number of doctors practicing in hospitals and other areas, resulting in the limited development of economic and social resilience systems and affecting the normal functioning of the urban system. (4) 2014-2017: The urban resilience index of the Yangtze River Delta showed a significant growth trend starting in 2014. This was the first year of China's comprehensive deepening of reform, where livelihood policies were adjusted to reflect the economic development. For the first time, China's government work report offered multiple prescriptions for urban diseases and 
committed to deepening reforms and advancing environmental governance; it has seen a sustained growth trend thereafter, as indicated by the linear resilience index curve. China's urban resilience index for the Yangtze River Delta rose from 0.1790 in 2003 to the final 0.2078. Overall, urban resilience in China's Yangtze River Delta is showing a sustained growth trend.

\subsection{Analysis of the annual average index value for urban resilience}

Figure 3 is based on the annual weighted average index of cities in each region from 2003 to 2007. From the histogram of urban resilience for the Yangtze River Delta, the urban resilience index formed by urban agglomerations from 2003 to 2017 shows the following: (1) Taking the urban resilience indexes of Shanghai, Nanjing, Suzhou, Hangzhou, and Hefei as the core, a decreasing trend can be seen in the surrounding cities. This occurs because Nanjing, Hangzhou, and Hefei are the core cities of China's provinces, while Shanghai and Suzhou are economically developed cities. (2) Shanghai is China's international economic, financial, trade, shipping, science and technology innovation center; in the overall development of the urban system, some of the remaining cities, such as Nanjing, Soochow, Hangzhou, and Hefei, are of medium resilience, while the rest show high resilience in the face of the COVID-19 pandemic. The urban resilience indices for many cities are at lower levels, and the differences between them are not significant. (3) The results of the entropy-weighted TOPSIS model provide the annual average of urban resilience in the Yangtze River Delta from 2003 to 2017. The weighted average index ranking is as follows: Shanghai $(0.8115)>$ Nanjing $(0.4493)>$ Hangzhou (0.3697) $>$ Soochow $\quad(0.3385)>$ Hefei $\quad(0.2480)>$ Wuxi $(0.2436)>$ Ningbo $\quad(0.2432)>$ Nantong $\quad(0.2017)>$ Shaoxing $\quad(0.1840)>$ Yancheng
$(0.1824)>$ Changzhou
$(0.1698)>$ Lu'an
$(0.1687)>$ Jinhua
$(0.1669)>$ Taizhou

$(0.1663)>$ Jiaxing

(0.1606) $>$ Anqing

$(0.1557)>$ Fuyang

$(0.1547)>$ Yangzhou

$(0.1526)>$ Chuzhou

$(0.1437)>$ Wuhu

$(0.1426)>$ Huzhou

$(0.1399)>$ Taizhou

$(0.1398)>$ Zhenjiang

$(0.1354)>$ Huaibei

$(0.1324)>$ Soochow

(0.1306) > Tongling

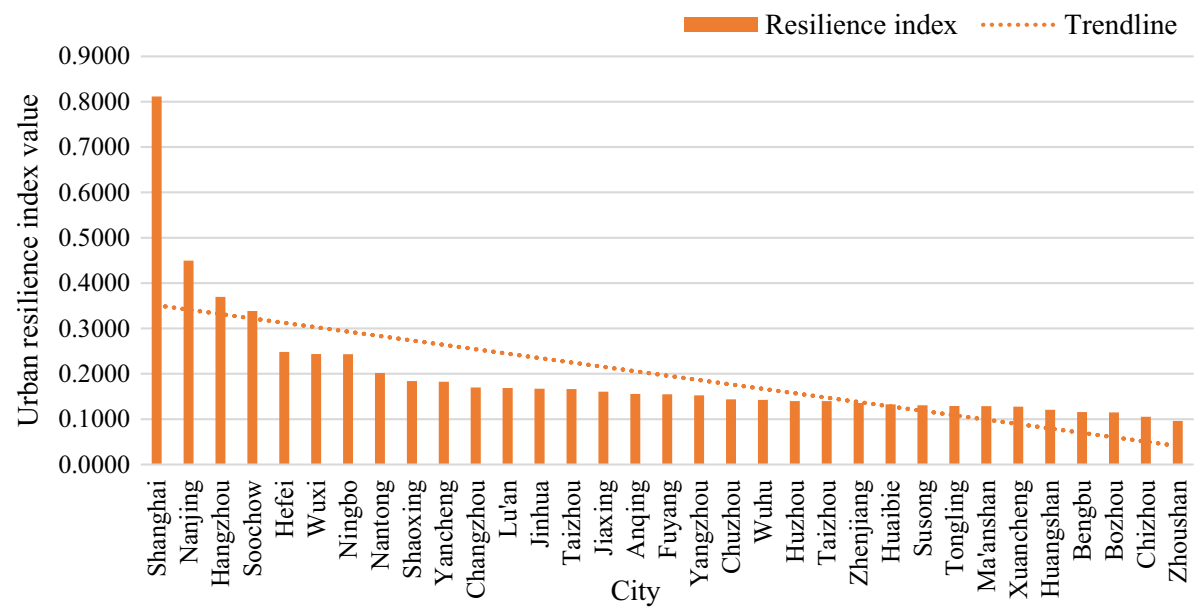

Fig. 3 Average value for the urban resilience index in the Yangtze River Delta 
$(0.1292)>$ Maanshan $(0.1288)>$ Xuancheng $(0.1277)>$ Huangshan $(0.1205)>$ Bengbu $(0.1155)>$ Bozhoum (0.1147) $>$ Chizhou (0.1051) > Zhoushan (0.0961).

\subsection{Temporal variation in urban resilience}

The Chinese economy has a 10-year juggernaut-like economic cycle that consists of two smaller five-year cycles associated with the five-year plans that have been in place since the founding of New China. The five-year plan originated in the Soviet Union and now forms the central government's overall plan for economic development over each five-year period. The resilience development of the Yangtze River Delta over the past 15 years based on the response to the neo-coronavirus pandemic scenario can be similarly examined with a cyclical division of time based on economic cycle conditions for the years 2003, 2008, 2013, and 2017, respectively, according to the natural breakpoint hierarchy in the histogram (Hossain and Rahman 2017). Under the COVID-19 scenario, the resilience index values of cities in the Yangtze River Delta in 2003 were classified as follows: low (0.117212015-0.148670925), medium (0.148670926-0.213956945), high (0.213956946-0.410718277), and higher (0.410718278-0.799427671). Four periods representing 5-year intervals were selected and compared: 2003, 2008, 2013, and 2017. The results are as follows (Fig. 4): (1) In 2003, the highest urban resilience in the Yangtze River Delta was 0.7994 in Shanghai; this is mainly because Shanghai is an international economic, financial, trade, and shipping center, with increasingly improved economic, ecological planning, infrastructure construction and social policies, and a strong public service and health system. The data analysis shows that in 2003, the ranking of cities in resilience is as follows: Nanjing (0.4107) $>$ Hangzhou (0.3277). The middle urban resilience index is ranked as follows: Soochow $(0.2140)>$ Ningbo $(0.1997)>$ Hefei $(0.1854)>$ Wuxi $(0.1819)>$ Jinhua $(0.1643)>$ Lu' an $(0.1641)>$ Anqing $(0.1612)>$ Jiaxing $(0.1567)>$ Nantong $(0.1551)>$ Yancheng $(0.1543)>$ Shaoxing $(0.1520)>$ Chuzhou $(0.1508)>$ Changzhou $(0.1487)>$ Xuancheng $(0.1435)$. The other cities are at a low resilience level and will be extremely vulnerable to the pandemic. (2) In 2008, Nanjing (0.4494) rose to become a high

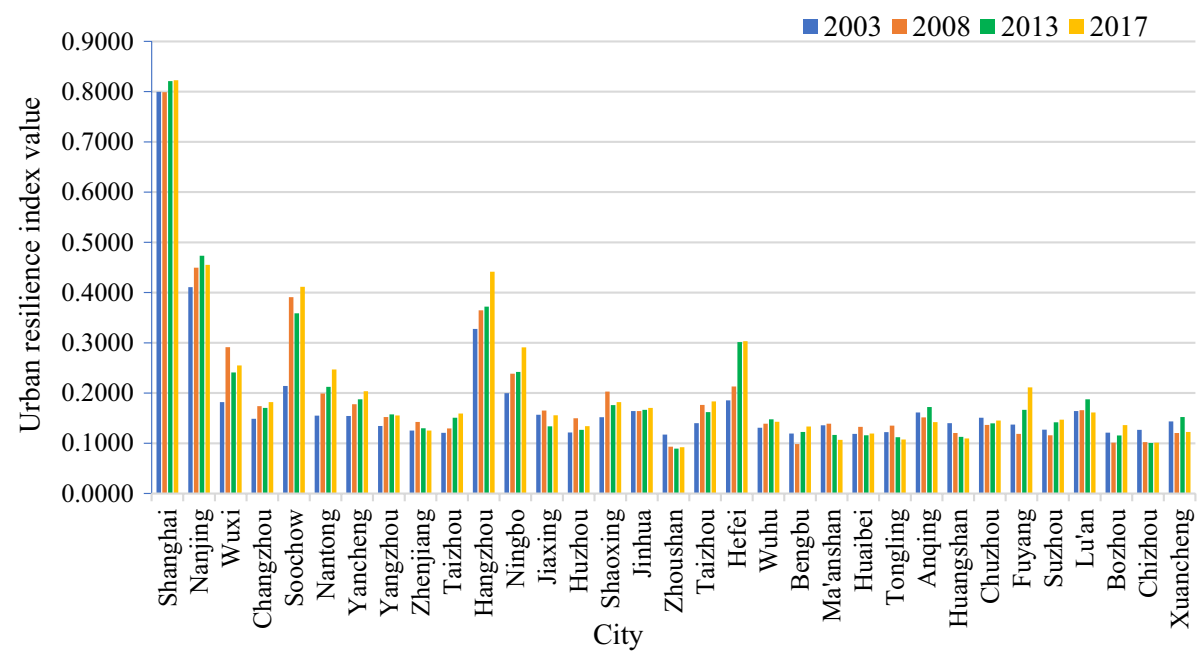

Fig. 4 Temporal variation in urban resilience in the Yangtze River Delta a 2003; b 2008; c 2013; d 2017 
resilience level urban area; Soochow (0.3908), Wuxi (0.2914), and Ningbo (0.2385) started to rise to higher levels of resilience, with Soochow, in particular, becoming more resilient. Hefei rose to a high level of urban resilience in 2013, Hangzhou rose to higher urban resilience levels in 2017, and Nantong rose to high urban resilience levels. Resilience is improving overall, but resilience levels have decreased in some cities. (3) The main reason for the current resilience levels is the prominent position of Shanghai as an economic hub connecting the international and domestic markets. Shanghai has certain medical resources and corresponding supporting technologies, and its high economic development has provided substantial material support for its response to the pandemic. The continuous improvement in the resilience indices of Soochow and Wuxi is due to the spillover effect from Shanghai's high attractiveness to international resources. The successful integration of Soochow and Wuxi with the Shanghai economy, as well as Shanghai's growing economic strength and international influence, has led to the emergence of new markets such as Nanjing, Hangzhou, and Soochow. Cities such as Ningbo have begun to take the initiative to draw closer to Shanghai and have positive interaction with the Shanghai economy in terms of international competition and cooperation. In addition to the unique geographical advantages and economic, ecological and social policy advantages of Wuxi, Taizhou, and Yangzhou are also becoming fully integrated into South Jiangsu, and in this process, Shanghai's influence is further accepted. Hangzhou, Ningbo, and other cities around the Hangzhou Bay metropolitan area have also accelerated the construction of "South Shanghai," with the construction of the Hangzhou Bay Bridge, the big and small Yangshan Port, and other cities in the urban area. The construction of Beilun Port is another opportunity to launch a comprehensive connection with Shanghai in the fields of economy, ecology, infrastructure, and social policy construction.

\subsection{Spatial variation in urban resilience}

The spatial distribution of urban resilience to the COVID-19 pandemic in the Yangtze River Delta is sequentially distributed (Fig. 5), and the changes in the spatial pattern of urban resilience in the Yangtze River Delta city cluster since 2003 can be divided into four time points. First, in 2003, the Yangtze River Delta urban cluster formed a dotted layout, with Shanghai as the core and Nanjing and Hangzhou as secondary cores. The indices were 0.7994, 0.4107, and 0.3277, respectively, reflecting a wide difference in resilience. First stage: From 2003 to 2008, the urbanization process in the Yangtze River Delta was slow, and the urban pattern changed little. In 2008, the resilience spatial distribution of the Yangtze River Delta urban agglomeration was centered on Shanghai (0.7989), Nanjing (0.4494), Soochow (0.3908), Hangzhou (0.3646), Wuxi (0.2914), and Ningbo (0.2385). The second stage: from 2008 to 2013, the Yangtze River Delta urban agglomeration formed with Shanghai (0.8209) and Nanjing (0.4733) as the core and Hangzhou (0.3721), Soochow (0.3588), Hefei (0.3013), Ningbo (0.2422), and Wuxi (0.2411) as the subcore. In the third stage, from 2013 to 2017, Shanghai (0.8225), Nanjing (0.4552), Hangzhou (0.4417), and Soochow (0.4415) formed the core, while Hefei (0.3032), Ningbo (0.2908), Wuxi (0.2551), and Nantong (0.2470) were the subcore.

Due to the different economic and urban social policies in each period, the different urban resilience indices show exponential type or scale distributions in each period. In the 1960s and 1970s, China implemented a policy of controlling large cities, and the population of megacities was effectively controlled. The primacy of cities decreased, and the order curves of the urban resilience index in most cities showed a smooth trend (Fig. 2). 


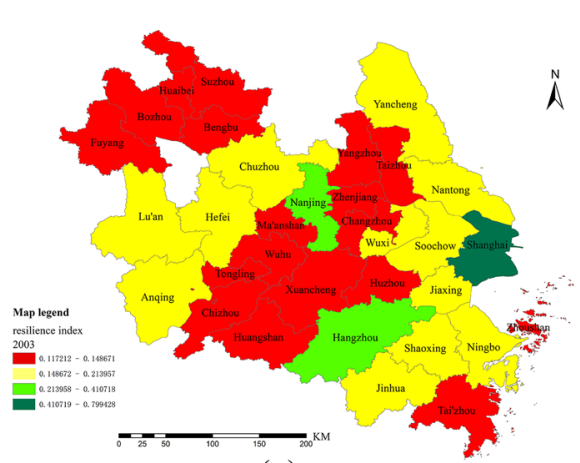

(a)

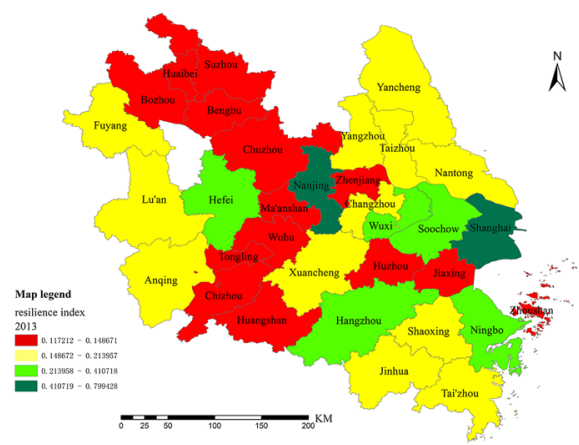

(c)

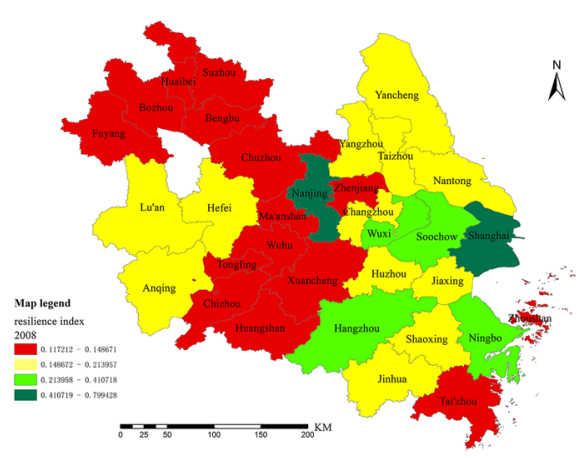

(b)

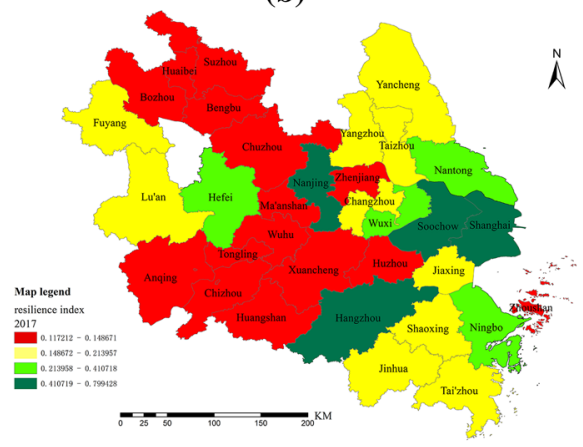

(d)

Fig. 5 Spatial variation in urban resilience in the Yangtze River Delta a 2003; b 2008; c 2013; d 2017

However, the urban resilience index of Shanghai still ranked highest due to the influence of national economic policies and social resources; for example, urban road area is included in the index, which to a certain extent represents Shanghai's accessibility. This allows timely medical treatment and corresponding measures to be taken during the pandemic. In 2010, Hangzhou rose to become a core urban area with a high urban resilience index due to the opening of rail lines such as the Shanghai-Hangzhou railway and the growth of Shanghai's role in imports and exports. Driven by trade, light industry is developing rapidly. Since the start of the new century, the Internet economy has become the new economic growth point for Hangzhou, driven by high-tech companies such as Alibaba. Continuous urban development, infrastructure, and social policies are key to improving Hangzhou's resilience index.

The characteristics of the spatial structural distribution of urban resilience in the Yangtze River Delta under COVID-19 include (1) geographic distribution patterns. The main distribution of the urban agglomeration-type urban resilience index is polycentric, i.e., centered on the high urban resilience index of large cities. (2) In this urban geographic location, the urban resilience index is mainly distributed in the east and in the capital cities of Jiangsu, Zhejiang, and Anhui provinces, as well as in urban areas. Shanghai is dominated by large cities, which decrease in size from east to the west and from the coastal to the inland resilience index. (3) In terms of the type of index distribution, cities with low urban resilience indices oriented to COVID-19 are mainly located in the inland region, and cities in Anhui Province have a wide distribution of low urban resilience indices. 


\subsection{Improvement strategy for urban resilience}

Based on the above analysis of the spatial and temporal evolution of the chronological characteristics of Yangtze River Delta cities, it can be seen that the economic resilience of the Yangtze River Delta has generally increased, and the center of gravity of the Yangtze River Delta is moving. The spatial differences in regional resilience have generally narrowed as a result of the northwestward shift. However, at present, the regional economic resilience within the Yangtze River Delta is still unevenly distributed, and there are significant internal differences among provinces. Resilience has yet to be enhanced. Based on this and in light of the preceding analysis, the following recommendations are made:

1. Take advantage of foreign urban resilience research, such as the US Rockefeller Foundation in May 2013 and implementation of the "Global 100 Resilient Cities" project (Fitzgibbons and Mitchell 2019). A total of four Chinese cities, Yiwu, Haiyan, Huangshi, and Deyang, were selected for this project and have already achieved results. China has applied to join the Global 100 Resilient Cities program, seeking domestic and international cooperation to secure funding, expertise, and technology. The government should support the development of urban resilience by learning from other countries, working together to improve the overall resilience of the region, and fully absorbing the challenges of the international community. Urban resilience building can use experiences to improve the overall resilience of cities in pandemic scenarios and the overall resilience to epidemics. The Yangtze River Delta also needs to learn relevant measures from the urban areas selected for the project to construct urban resilience according to local conditions. Four domestic cities require focus on the resilience of urban construction and specific measures, including a comprehensive analysis of their own actual situation and a reasonable reference for effective measures; in addition, there is a need to actively participate in the construction of pandemic-related meetings and to learn from the latest research results and practical experience to support the sustainable development of their own urban resilience and enhance their path.

2. Urban economic resilience is an important component of urban resilience and includes urban ecological environment resilience, urban social system resilience, urban infrastructure resilience, and other components. Urban economic resilience can also be subdivided into annual GDP, local fiscal budget expenditures, etc. Urban ecological resilience can be divided into garden green areas, green coverage rates of built-up areas, etc. The resilience of urban infrastructure can be divided into hospitals, number of health centers, number of beds in hospitals, and so on. The resilience of the urban social system can be divided into population density, urban unemployment registration number, and so on. These factors are interrelated, the whole affects the parts, and the parts affect the whole as well. Therefore, to improve the economic resilience of cities in the Yangtze River Delta, it is necessary to promote the coordinated development of urban economic resilience, the ecological environment, infrastructure resilience and social systems to improve overall urban resilience and give play to the role of the part (urban resilience) in promoting the whole (urban resilience under the pandemic scenario). First, the development of urban resilience is the balanced development of infrastructure and public services; consensus has been achieved on the role of balance to promote the coordinated development of cities. We should further promote the balanced development of urban infrastructure and public services and properly handle the relationship between economic and social development and ecological and environmental protec- 
tion. In particular, in the process of promoting the coordinated development of urban economic and ecological resilience, efforts should be made to protect and improve the ecological environment in terms of the comprehensive utilization of resources and the spatial distribution of industries.

3. The areas with high values in the urban resilience index are mainly concentrated in the east-central Yangtze River Delta and the southeastern riverside and seaside areas and mainly include provincial capitals, the city center of Shanghai, and its peripheral regions. These areas of high economic resilience need to continue to develop their economies, maintain stable macroeconomic conditions, and continuously adjust their industrial structures by attracting foreign investment, increasing economic diversification, supporting patent applications, ensuring the quantity and quality of university students, and increasing the innovative capacity of the economy to enhance the economic resilience of the region, thereby increasing the economic base for responding to the COVID-19 pandemic. They also must strengthen the ecological system to improve the quality of the residential environment and improve the medical infrastructure and the expertise of doctors to better address the pandemic by increasing physician literacy, strengthening the promotion of professional knowledge, and implementing a core region-driven strategy to promote the Shanghai, Nanjing, Zhejiang, and Hangzhou areas. In addition, the region should strengthen interregional transportation and communication facilities, improve interregional road and information networks, ensure circulation and connection between areas with a high resilience index and those with low resilience, and provide funds, technology, high-quality information, and prevention and control experience to areas with low resilience in a timely manner to effectively respond to COVID-19.

4. The areas with low urban resilience indices are concentrated in the northern and southwestern parts of the Yangtze River Delta, mostly in Anhui Province, with some areas in Jiangsu and Zhejiang provinces. Therefore, efforts should be made to develop local resources for the challenging low-value areas of Anhui Province, especially economically less advanced areas such as Fuyang, Bozhou, and Soochow. Advantageous conditions exist, and they could seize the strategic opportunity of the "rise of central China" and seek financial support from the state. They could rely on the driving effect of the nearest provincial capital city, Hefei's, and actively engage with Shanghai, Nanjing, and Hangzhou and other cities to promote the development of China. They can continue to shift industries to other regions and develop economic industries with local characteristics to optimize the industrial structure and improve the economy by combining local advantages and conditions. This diversity will provide an adequate economic basis for dealing with the new coronavirus, in addition to actively attracting industries. The process of the industry transfer of capital, technology, human resources, and experience in outbreak response and management can improve local response capacity while promoting local economic development. Increasing per capita disposable income, thereby retaining the population, attracting foreigners, increasing economic activity and employment, and thereby increasing the number of jobs will rebuild urban resilience in the wake of the coronavirus pandemic. 


\section{Conclusions}

By constructing an urban resilience evaluation system, the resilience of the Yangtze River Delta cities under the pandemic scenario was evaluated. The results can provide a quantitative basis for urban resilience assessment under the pandemic scenario to provide a reference to help cities in different regions to improve urban resilience in the future. Based on the above research, the following four dimensions of the new coronavirus pandemic scenario were constructed: economy, ecology, infrastructure, and social systems. A comprehensive assessment index system for urban resilience in the Yangtze River Delta was built to quantitatively assess the urban resilience of the Yangtze River Delta and reveal its overall timing and spatial heterogeneity. Examining different regions to explore the influencing factors led to the following conclusions: Through the construction of an urban resilience evaluation system, the pandemic-based evaluation of the resilience of Yangtze River Delta cities under the pandemic scenario provides an operational and quantitative basis for the assessment of urban resilience under the pandemic scenario. This study provides lessons for improving the resilience of cities in different geographies across China. Based on the above research, the four dimensions of economic, ecological, infrastructural, and social systems were used to construct a new coronavirus pandemic scenario. A comprehensive assessment index system for urban resilience in the Yangtze River Delta was created to quantitatively assess the urban resilience of the Yangtze River Delta and reveal its overall timing and spatial heterogeneity. The following conclusions were drawn from the impact factor analysis of different regions.

1. The resilience of the Yangtze River Delta urban cluster under the COVID-19 pandemic shows a continuous growth trend, although there are differences in the growth rate and trend. The 2003-2004 period saw faster growth, followed by a short-term decline until 2008. Following this continued slow growth, until the first year of China's comprehensive deepening of reform in 2014, local livelihood policies focused on accelerating the adjustment, unswervingly deepening reform, and promoting environmental governance, resulting in a continuous growth trend.

2. The resilience structure of the Yangtze River Delta urban cluster under the COVID-19 pandemic scenario focuses on Shanghai, Nanjing, Soochow, Hangzhou, and Hefei as the core, with the surrounding cities as the spokes. The Yangtze River Delta sees less distribution of the high resilience urban clusters and greater distribution of clusters at the higher and medium resilience levels, but most of the urban clusters fall into the low resilience index.

3. From the spatial distribution point of view, the growth differences within the Yangtze River Delta urban clusters under the COVID-19 pandemic are obvious; the spatial local characteristics show that the urban resilience index of the Yangtze River Delta is spatially clustered, with the capital cities of Jiangsu, Zhejiang, Anhui and large cities in Shanghai as the main focus, decreasing from east to the west and decreasing from coastal to inland.

4. The pandemic should lead to a response based on the actual situation of urban construction, focusing on the people; establishing health, safety, and grassroots livelihood protection; improving the medical security system and urban medical institutions; unifying and coordinating development; actively attracting capital, technology, talent and pandemic response, and management experience through industrial transfer from other countries; promoting local economic recovery and development; implementing green, resilience, 
and health concepts; promoting improvements in the quality of urban development; and formulating reasonable planning policies to take advantage of the relationship between the whole and the parts.

\section{Discussion}

This paper selects economic, ecological, infrastructural, and social policy indicators to assess the overall level of resilience in the Yangtze River Delta under the COVID-19 pandemic scenario. This assessment and comparative study of temporal and spatial variation can support future response to the pandemic and thus effective organization and management, thereby leading to improvements in urban resilience. The impact is critical. In dealing with and responding to epidemics, elements such as the governance of urban social policies need to play a leading role in the process of adjustment and adaptation.

Although this study has contributed to knowledge about the prevention and treatment of COVID-19, there are still many deficiencies. First, the indicator system is not perfect and lacks directly related indicators due to limitations of the discipline, so it is impossible to provide an in-depth understanding and analysis of COVID-19. In future studies, we will continuously enhance our in-depth understanding of the pandemic area and further improve the indicator system. In the process of sorting and ranking, this paper summarized the role of resilience in the prevention and treatment of COVID-19 from the national level. Although the experiences here can be used for reference in the prevention and control of COVID-19, its replicability is still insufficient. In the future, the urban infectious disease prevention and control systems in developed countries should be further summarized. Finally, the evaluation method needs to be updated constantly. At present, the most accurate risk assessment method is carried out based on scenario simulation, but there are few studies using this method in the field of urban resilience assessment. Therefore, scholars need to work together to enrich the application of this method in the field of COVID19 to improve the urban plasticity evaluation system, effectively prevent and control the coronavirus pandemic, ensure the protection of life, and strengthen the property of urban resilience.

Funding This research was funded by the National Natural Science Foundation of China (Grant Number: 41401600).

\section{Compliance with ethical standards}

Conflict of interest The authors declare no conflicts of interest.

\section{References}

Bellamy CC, van der Jagt APN, Barbour S, Smith M, Moseley D (2017) A spatial framework for targeting urban planning for pollinators and people with local stakeholders: a route to healthy, blossoming communities? Environ Res 158:255-268. https://doi.org/10.1016/j.envres.2017.06.023 
Beskese A, Demir HH, Ozcan HK, Okten HE (2015) Landfill site selection using fuzzy AHP and fuzzy TOPSIS: a case study for Istanbul. Environ Earth Sci 73:3513-3521. https://doi.org/10.1007/s1266 5-014-3635-5

Boland P, Fox-Rogers L, McKay S, Murtagh B (2020) Illegal geographies and spatial planning: developing a dialogue on drugs. Territ Polit Gov 8:177-203. https://doi.org/10.1080/21622671.2018.1503092

Bonanno GA, Galea S, Bucciarelli A, Vlahov D (2007) What predicts psychological resilience after disaster? The role of demographics, resources, and life stress. J Consult Clin Psychol 75:671-682. https:// doi.org/10.1037/0022-006x.75.5.671

Bostick TP, Connelly EB, Lambert JH, Linkov I (2018) Resilience science, policy and investment for civil infrastructure. Reliab Eng Syst Saf 175:19-23. https://doi.org/10.1016/j.ress.2018.02.025

Bozza A, Asprone D, Manfredi G (2015) Developing an integrated framework to quantify resilience of urban systems against disasters. Nat Hazards 78:1729-1748. https://doi.org/10.1007/s11069-015-1798-3

Bruneau M, Chang S, Eguchi R, Lee G, O'Rourke T, Reinhorn A, Shinozuka M, Tierney K, Wallace W, Winterfeldt D (2003) A framework to quantitatively assess and enhance the seismic resilience of communities. Earthq Spectra 19:733-752. https://doi.org/10.1193/1.1623497

Cariolet JM, Colombert M, Vuillet M, Diab Y (2018) Assessing the resilience of urban areas to trafficrelated air pollution: application in Greater Paris. Sci Total Environ 615:588-596. https://doi. org/10.1016/j.scitotenv.2017.09.334

Chang SE, McDaniels T, Fox J, Dhariwal R, Longstaff H (2014) Toward disaster-resilient cities: characterizing resilience of infrastructure systems with expert judgments. Risk Anal 34:416-434. https://doi. org/10.1111/risa.12133

Chen X, Li X (2013) Group decision making based on novel trapezoidal intuitionistic fuzzy TOPSIS method. Control Decis 28:1377-1381. https://doi.org/10.1016/j.cie.2013.06.031

Chen Y, Tao L, Chen R, Zhao M (2020) Influence of the built environment on community flood resilience: evidence from Nanjing City, China. Sustainability 12:2401. https://doi.org/10.3390/su120 62401

Chirisa I, Bandauko E, Mazhindu E, Kwangwama NA, Chikowore G (2016) Building resilient infrastructure in the face of climate change in African cities: scope, potentiality and challenges. Dev South Afr 33:113-127. https://doi.org/10.1080/0376835X.2015.1113122

Cho S, Chang H (2017) Recent research approaches to urban flood vulnerability, 2006-2016. Nat Hazards 88:633-649. https://doi.org/10.1007/s11069-017-2869-4

Clarke SE (2017) Local place-based collaborative governance: comparing state-centric and society-centered models urban. Aff Rev 53:578-602. https://doi.org/10.1177/1078087416637126

Croese S, Green C, Morgan G (2020) Localizing the sustainable development goals through the lens of urban resilience: lessons and learnings from 100 resilient cities and cape town. Sustainability 12:550. https://doi.org/10.3390/su12020550

Cutter S, Barnes L, Berry M, Burton C, Evans E, Tate E, Webb J (2008) A place-based model for understanding community resilience to natural disasters. Glob Environ Change 18:598-606. https://doi. org/10.1016/j.gloenvcha.2008.07.013

Cutter S, Ash K, Emrich C (2014) The geographies of community disaster resilience. Glob Environ Change 57:134-136. https://doi.org/10.1016/j.gloenvcha.2014.08.005

Dennis M, Scaletta KL, James P (2019) Evaluating urban environmental and ecological landscape characteristics as a function of land-sharing-sparing, urbanity and scale. PLoS ONE 14:57-66. https:// doi.org/10.1371/journal.pone.0215796

Diaz-Sarachaga JM, Jato-Espino D (2019) Do sustainable community rating systems address resilience? Cities 93:62-71. https://doi.org/10.1016/j.cities.2019.04.018

Dutta B, Singha T, Goh M, Lamata MT, Verdegay JL (2019) Post factum analysis in TOPSIS based decision making method. Expert Syst Appl 138:112806. https://doi.org/10.1016/j.eswa.2019.07.023

Fang D, Li Z, Li N, Han L, Wu J, Lu X, Kong X, Li Y (2017) Urban resilience: a perspective of system of systems in trio spaces China. Civil Eng J 50:1-7. https://doi.org/10.1016/j.landurbpla n.2017.01.023

Fastiggi M, Meerow S, Miller TR (2020) Governing urban resilience: organisational structures and coordination strategies in 20 North American city governments. House Theory Soc 29:25-57. https:// doi.org/10.1016/j.cosust.2020.02.002

Fitzgibbons J, Mitchell CL (2019) Just urban futures? Exploring equity in "100 Resilient Cities." World Dev 122:648-659. https://doi.org/10.1016/j.worlddev.2019.06.021

Folke C, Carpenter S, Walker B, Scheffer M, Elmqvist T, Gunderson L, Holling CS (2004) Regime shifts, resilience and biodiversity in ecosystem management. Annu Rev Ecol Evol Syst 35:557581. https://doi.org/10.1146/annurev.ecolsys.35.021103.105711 
Herbeck J, Flitner M (2019) Infrastructuring coastal futures: key trajectories in Southeast Asian megacities. J Geogr Soc Berl 150:118-130. https://doi.org/10.12854/erde-2019-451

Holling CS (1973) Resilience and stability of ecological systems. Annu Rev Ecol Syst 4:1-23. https:// doi.org/10.1146/annurev.es.04.110173.000245

Hossain M, Rahman MAU (2017) Pro-poor adaptation for the urban extreme poor in the context of climate change: a study on Dhaka City, Bangladesh. Int J Clim Change Strateg Manag 10:389-406. https://doi.org/10.1108/IJCCSM-08-2016-0117

Hossain NUI, Jaradat R, Hosseini S, Marufuzzaman M, Buchanan RK (2019) A framework for modeling and assessing system resilience using a Bayesian network: a case study of an interdependent electrical infrastructure system. Int J Crit Infrastruct Prot 25:62-83. https://doi.org/10.1016/j.ijcip.2019.02.002

Huang L, Wang Y, Liu J, Ye P, Cheng B, Xu H, Qu H, Ning G (2020) Factors associated with resilience among medical staff in radiology departments during the outbreak of 2019 novel coronavirus disease (COVID-19): a cross-sectional study. Med Sci Monit 26:e925669. https://doi.org/10.12659/ msm.925669

Huck A, Monstadt J, Driessen P (2020) Building urban and infrastructure resilience through connectivity: an institutional perspective on disaster risk management in Christchurch, New Zealand. Cities 98:102573. https://doi.org/10.1016/j.cities.2019.102573

Inoue H, Todo Y (2019) Firm-level propagation of shocks through supply-chain networks. Nat Sustain 2:2841-2847. https://doi.org/10.1038/s41893-019-0351-x

Jones MI, Parker JK (2019) An analysis of the size and direction of the association between mental toughness and Olympic distance personal best triathlon times. J Sport Health Sci 8:71-76. https:// doi.org/10.1016/j.jshs.2017.05.005

Klimek P, Varga J, Jovanovic A, Székely Z (2019) Quantitative resilience assessment in emergency response reveals how organizations trade efficiency for redundancy. Saf Sci 113:404-414. https:// doi.org/10.1016/j.ssci.2018.12.017

Kuo M, Barnes M, Jordan C (2019) Do experiences with nature promote learning? Converging evidence of a cause-and-effect relationship. Front Psychol 10:305. https://doi.org/10.3389/fpsyg.2019.00305

Lafortezza R, Sanesi G (2019) Nature-based solutions: settling the issue of sustainable urbanization. Environ Res 172:394-398. https://doi.org/10.1016/j.envres.2018.12.063

Lankao PR (2010) Water in Mexico City: What will climate change bring to its history of water-related hazards and vulnerabilities? Environ Urban 22:157-178. https://doi.org/10.1177/095624780936263 6

Lhomme S, Serre D, Diab Y, Laganier R (2013) Analyzing resilience of urban networks: a preliminary step towards more flood resilient cities. Nat Hazards Earth Syst Sci 13:221-230. https://doi. org/10.5194/nhess-13-221-2013

Li M, Wang H, Wang H (2019) Resilience assessment and optimization for urban rail transit networks: a case study of beijing subway network. IEEE Access 1:11-17. https://doi.org/10.1109/ACCES S.2019.2919105

Macaskill K (2019) Public interest and participation in planning and infrastructure decisions for disaster risk management. Int J Disaster Risk Reduct 39:101200. https://doi.org/10.1016/j.ijdrr.2019.101200

Manyena SB (2006) The concept of resilience revisited. Disasters 30:433-450. https://doi.org/10.111 1/j.0361-3666.2006.00331.x

Moghadas M, Asadzadeh A, Vafeidis A, Fekete A, Kötter T (2019) A multi-criteria approach for assessing urban flood resilience in Tehran, Iran. Int J Disaster Risk Reduct 35:101069. https://doi. org/10.1016/j.ijdrr.2019.101069

Muñoz-Erickson TA, Lugo AE, Quintero B (2014) Emerging synthesis themes from the study of socialecological systems of a tropical city. Ecol Soc 19:89-94. https://doi.org/10.5751/ES-06385-190323

Ompad DC, Palamar JJ, Krause KD, Kapadia F, Halkitis PN (2018) Reliability and validity of a material resources scale and its association with depression among young men who have sex with men: the P18 cohort study. Am J Mens Health 12:1384-1397. https://doi.org/10.1177/1557988316651206

Orencio PM, Fujii M (2013) A localized disaster-resilience index to assess coastal communities based on an analytic hierarchy process (AHP). Int J Disaster Risk Reduct 3:62-75. https://doi.org/10.1016/j. ijdrr.2012.11.006

Paidakaki A, Moulaert F (2018) Disaster resilience into which direction(s)? Competing discursive and material practices in post-katrina New Orleans. House Theory Soc 35:432-454. https://doi. org/10.1080/14036096.2017.1308434

Percy DB, Streith L, Wong H, Ball CG, Widder S, Hameed M (2019) Mental toughness in surgeons: is there room for improvement? Can J Surg 62:482-487. https://doi.org/10.1503/cjs.010818 
Rees T, Hardy L, Güllich A, Abernethy B, Côté J, Woodman T, Montgomery H, Laing S, Warr C (2016) The great British medalists project: a review of current knowledge on the development of the world's best sporting talent. Sports Med 46:1041-1058. https://doi.org/10.1007/s40279-016-0476-2

Sherrieb K, Norris F, Galea S (2010) Measuring capacities for community resilience. Soc Indic Res 99:227-247. https://doi.org/10.1007/s11205-010-9576-9

Stanke C, Murray RA, Nurse J, Williams R (2012) The effect of flooding on mental health: outcomes and recommendations from a review of the literature. Publ Libr Sci Curr Disaster 47:37-43. https:// doi.org/10.1016/j.jenvman.2019.05.028

Tkatch R, Musich S, MacLeod S, Kraemer S, Hawkins K, Wicker ER, Armstrong DG (2017) A qualitative study to examine older adults' perceptions of health: keys to aging successfully. Geriatr Nurs 38:485-490. https://doi.org/10.1016/j.gerinurse.2017.02.009

Trencher G, Castán Broto V, Takagi T, Sprigings Z, Nishida Y, Yarime M (2016) Innovative policy practices to advance building energy efficiency and retrofitting: approaches, impacts and challenges in ten C40 cities. Environ Sci Policy 66:353-365. https://doi.org/10.1016/j.envsci.2016.06.021

Ujeyl G, Rose J (2015) Estimating direct and indirect damages from storm surges: the case of Hamburg Wilhelmsburg. Coast Eng J 57:132-146. https://doi.org/10.1142/S0578563415400069

Vejmelková E, Keppert M, Rovnanikova P, Keršner Z, Černý R (2012) Properties of lime composites containing a new type of pozzolana for the improvement of strength and durability. Compos B Eng 43:3534-3540. https://doi.org/10.1016/j.compositesb.2011.11.053

Wang YM, Elhag TMS (2006) Fuzzy TOPSIS method based on alpha level sets with an application to bridge risk assessment. Expert Syst Appl 31:309-319. https://doi.org/10.1016/j.eswa.2005.09.040

Wang W, Yang S, Hu F, Stanley HE, He S, Shi M (2018) An approach for cascading effects within critical infrastructure systems. Phys A Stat Mech Appl 510:164-177. https://doi.org/10.1016/j.physa .2018 .06 .129

Wang C, Pan R, Wan X, Tan Y, Xu L, Ho CS, Ho RC (2020a) Immediate psychological responses and associated factors during the initial stage of the 2019 coronavirus disease (COVID-19) epidemic among the general population in China. Int J Environ Res Public Health 17:1279. https://doi.org/10.3390/ijerp h17051729

Wang Y, Hulse D, Von Meding J, Brown M, Dedenbach L (2020b) Conceiving resilience: lexical shifts and proximal meanings in the human-centered natural and built environment literature from 1990 to 2018. Dev Built Environ 1:100003. https://doi.org/10.1016/j.dibe.2019.100003

Wilson PA, Valera P, Martos AJ, Wittlin NM, Muñoz-Laboy MA, Parker RG (2016) Contributions of qualitative research in informing HIV/AIDS interventions targeting black MSM in the United States. J Sex Res 53:642-654. https://doi.org/10.1080/00224499.2015.1016139

Zhao D, Liu C, Feng X, Hou F, Xu X, Li P (2019) Menopausal symptoms in different substages of perimenopause and their relationships with social support and resilience. Menopause 26:233-239. https:// doi.org/10.1097/gme.0000000000001208

Zhong M, Lin K, Tang G, Zhang Q, Hong Y, Chen X (2020) A framework to evaluate community resilience to urban floods: a case study in three communities. Sustainability 12:1521. https://doi.org/10.3390/ su12041521

Zhou W, Martinón-Torres M, Chen J, Liu H, Li Y (2012) Distilling zinc for the Ming Dynasty: the technology of large scale zinc production in Fengdu, Southwest China. J Archaeol Sci 39:908-921. https://doi. org/10.1016/j.jas.2011.10.021

Publisher's Note Springer Nature remains neutral with regard to jurisdictional claims in published maps and institutional affiliations. 